\title{
Humic acid sorption properties of calcium-rich derivatives of Neapolitan Yellow Tuff
}

\author{
E. Coppola ${ }^{1}$, P. Iovino ${ }^{1}$, S. Salvestrini ${ }^{1}$, S. Capasso ${ }^{1} \&$ C. Colella ${ }^{2}$ \\ ${ }^{1}$ Dipartimento di Scienze Ambientali, \\ Seconda Università degli Studi di Napoli, Italy \\ ${ }^{2}$ Dipartimento di Ingegneria dei Materiali e della Produzione, \\ Università Federico II, Napoli, Italy
}

\begin{abstract}
With the objective of developing new agents for the removal of humic substances from water, the sorption properties of Ca-enriched Neapolitan Yellow Tuff (NYT), obtained by cation exchange at room temperature or by treatment with $\mathrm{CaCl}_{2}$ at high temperature, were tested. Sorption of humic acids onto NYT samples was evaluated at neutral $\mathrm{pH}$ and room temperature by batch sorption tests and dynamic experiments on small columns. The salt-thermal treatment gives rise to samples with higher calcium content and superior sorption ability. For all the samples tested the sorption capacity increased with the contact time between the solid phase and the humic acids solution. The Langmuir parameters of the sorption isotherms and the breakthrough curves recorded by dynamic experiments indicate that high-temperature Ca-enriched NYT exhibits sorption properties higher than that recorded for commercial activated carbon and at least comparable to those of other materials recently investigated.
\end{abstract}

Keywords: water purification; humic acid; zeolitic tuff, Ca-enriched zeolite.

\section{Introduction}

Humic substances (HS) are natural polymers containing aromatic blocks, with a broad molecular weight distribution and high chemical heterogeneity. Produced by biological decomposition of organic matter from plants and other organisms, they account for about $50-80 \%$ of the organic matter in water from lakes and rivers and other terrestrial sources. Typical total organic carbon values are 0.5 $\mu \mathrm{g} \mathrm{mL}^{-1}$ in seawater, $7 \mu \mathrm{g} \mathrm{mL}^{-1}$ in rivers and $25 \mu \mathrm{g} \mathrm{mL}{ }^{-1}$ in marshes and bogs. 
HS have a yellow to black appearance and consist of carbon, oxygen, hydrogen, sometimes small amounts of nitrogen and, occasionally, phosphorous and sulphur. HS have an acidic character due to the presence of carboxylic and phenolic groups. Depending on their solubility in water, HS are divided into fulvic acids (FA), humic acids (HA) and humins. The last ones are insoluble at any $\mathrm{pH}, \mathrm{HA}$ are soluble only at $\mathrm{pH}>2$, whereas $\mathrm{FA}$ are the fraction soluble at any $\mathrm{pH}$. The concentration of HS and FA in drinking water has to be very low, both for the unpleasant colour and taste that these substances impart and, mainly, for their negative effects on human health. HS are able to bind heavy metals and to adsorb hydrophobic toxic molecules; they may therefore facilitate the diffusion of these contaminants in the environment. Moreover, the treatment of HS-containing water with chlorine may produce toxic by-products such as $\mathrm{CHCl}_{3}$, a known human carcinogen.

Many methods have been developed to remove humic substances from water in drinking water treatment plants: coagulation/flocculation separation, ion exchange, adsorption by activated carbon and membrane filtration are among the most common [1, 2]. In recent years, other adsorbing materials have been proposed as HS-removing agents, including metal-modified silica gel, metal oxides (prevalently goethite) and aluminosilicate materials such as clay minerals and zeolites $[3,4]$. It has been shown that thermal treatment of a mixture containing magnesium, calcium or iron (III) salts and silica gel gives a silica gel derivative, containing metal atoms strongly linked to the silica surface, which are able to bind HS [2]. Goethite $(\alpha-\mathrm{FeOOH})$, a crystalline monohydrate form of ferric oxide, can interact with the carboxylic and phenolic groups of HS by means of the surface metal ions, giving almost irreversible adducts [5]. For the clay vermiculite, HS adsorption by the raw material was found to be negligible, whereas it increased markedly when the clay was modified by intercalation with poly(hydroxyl iron) or by ion exchange with a quaternary ammonium ion, hexadecyltrimethylammonium [6]. This quaternary ammonium ion has also been successfully used to increase the adsorption capability of the zeolite clinoptilonite [7] and the clay bentonite [8]. However, quaternary ammonium, iron and aluminum compounds should be used cautiously in water treatment plants, because their massive and sudden release could be dangerous for public health. According to the European directive 98/83/EC, $\mathrm{Fe}^{2+}$ and $\mathrm{Al}^{3+}$ concentrations in drinking water have to be below $200 \mathrm{mg} \mathrm{L}^{-1}$. Zeolites have received many practical applications in water purification, because of their excellent selective cation-exchange ability. Zeolites are three-dimensional aluminosilicates with negative charges on the framework that are balanced by cations such as alkali-metal and alkaline-earth ions. Their structures are characterized by channels and cages having dimensions of a few Angstroms [9]. Water softening and ammonium uptake by cation exchange are some of the more frequent practical applications of zeolite in water treatment.

In previous studies $[4,10,11]$ we have shown that the zeolite-rich Neapolitan Yellow Tuff (NYT) is able to bind HA through the action of surface extraframework exchangeable cations and that this ability is markedly enhanced when the zeolitic material is enriched with divalent cations, especially $\mathrm{Ca}^{2+}$, that 
may act as micro-bridges between the negative charges on the tuff and on the HA carboxylic groups. Here we report an investigation on the HA adsorbing properties of Ca-enriched NYT derivatives obtained by cation exchange at room temperature and by treatment with $\mathrm{CaCl}_{2}$ at $170^{\circ} \mathrm{C}$.

\section{Experimental}

\subsection{Materials}

The zeolitic tuff sample used in the present study comes from the huge formation of Neapolitan Yellow Tuff (NYT). This is the most recent (12,000 years ago) zeolitized formation of the Phlegraean Fields (Naples, Italy), which covers an area of about $13 \mathrm{~km}^{2}$ [12]. The typical composition and the physical-chemical properties of this rock have been reported previously [11]. Ancillary crystalline phases, recognized by X-ray diffraction analysis include analcime, smectite, Kfeldspar, pyroxene, and a trace of mica. Table 1 reports the screen analysis of the tuff sample examined.

Table 1: $\quad$ Screen analysis of the zeolitic tuff sample used in this study.

\begin{tabular}{cc}
\hline Screen size $(\mu \mathrm{m})$ & Cum. Passing wt \% \\
\hline 180 & 100.0 \\
125 & 87.5 \\
90 & 74.0 \\
63 & 58.5 \\
38 & 27.0 \\
\hline
\end{tabular}

Humic acids (HA) were obtained from Fluka and purified as previously reported [4]. The elemental contents, determined by a $\mathrm{CHN}$ analyzer, were: $\mathrm{C}=$ $63 \%, \mathrm{H}=5 \%, \mathrm{~N}=3 \%$ and $\mathrm{O}=29 \%$ by difference. The ash content, determined by keeping the sample in an oven at $600^{\circ} \mathrm{C}$ for $6 \mathrm{~h}$, was $<0.1 \%$, against a value of $20 \%$ declared by the producer for the non-purified product.

\subsection{Preparation of $\mathrm{Ca}^{2+}$-enriched sample by cation exchange at room temperature (type-1 derivative)}

The tuff was treated as reported formerly [4] with a slight modification. $3 \mathrm{~g}$ of NYT were mixed with $50 \mathrm{~mL}$ of a $2.0 \mathrm{M} \mathrm{CaCl}_{2}$ solution. The suspension was gently stirred for 1 day, centrifuged at $5000 \mathrm{rpm}$ for 30 minutes, and the supernatant solution was discharged. The whole procedure was repeated five times. Afterwards, the tuff was washed with distilled water and finally dried at $40^{\circ} \mathrm{C}$. A small amount of the product obtained was treated five times more as reported above. The total and exchangeable calcium content and HA adsorption ability of Ca-enriched samples produced by five and ten repeated cycles were identical within the experimental errors, showing that the cation amount exchanged with $\mathrm{Ca}^{2+}$ during the first round of five cycle was the highest possible in the conditions chosen. 


\subsection{Preparation of $\mathrm{Ca}^{2+}$-enriched samples by treatment with $\mathrm{CaCl}_{2}$ at $170^{\circ} \mathrm{C}$ (type-2 derivative)}

$28 \mathrm{~mL}$ of a $3.5 \mathrm{M} \mathrm{CaCl}_{2}$ solution were added to $14.0 \mathrm{~g}$ of NYT. The mixture was vigorously shaken for a few minutes, and then stored in an oven at $170^{\circ} \mathrm{C}$ for three days. The solid mixture was washed five times with $30 \mathrm{ml}$ of distilled water, then with dilute $\mathrm{CaCl}_{2}$ solution, [Ca] $=30 \mathrm{mg} \mathrm{L}^{-1}$, until the specific conductance of the water phase was coincident, within the experimental errors, with that of the washing solution. This treatment did not modify the zeolitic phase assemblage of the tuff sample, as checked by an X-ray powder diffraction analysis (Philips PW 1710 apparatus).

\subsection{Characterization of $\mathrm{Ca}^{2+}$-NYT aggregates}

Exchangeable calcium content: $40.0 \mathrm{~mL}$ of a $1 \mathrm{M}$ ammonium acetate solution were added to $1.0 \mathrm{~g}$ of the sample. The mixture was stored at room temperature for 1 day on a shaker at one oscillation per second. Afterwards the mixture was centrifuged and the amount of $\mathrm{Ca}$ in the water phase determined by atomic absorption spectrophotometry (Perkin Elmer AA100). The extraction with ammonium acetate was repeated until the metal concentration was coincident with that recorded in the starting solution (due to impurities of the salt).

Total calcium content: the samples were dissolved using the classical procedure with hydrofluoric acid followed by sulphuric acid. Afterwards, the amount of $\mathrm{Ca}$ in the acidic water phase was determined by atomic absorption spectrophotometry.

\subsection{Preparation of humic acid solutions}

$50 \mathrm{mg}$ of purified HA were suspended in $100 \mathrm{~mL}$ of $0.01 \mathrm{M}$ Tris/TrisHCl buffer (Tris = 2-amino-2-(hydroxymethyl)-1,3-propandiol), $\mathrm{pH} 7.2$, and vigorously stirred for 1 day to achieve complete dissolution. The $\mathrm{pH}$ was periodically tested, and, when required, adjusted with a few drops of Tris solution. The HA solution was added to a $0.01 \mathrm{M}$ Tris/TrisHCl solution containing $\mathrm{CaCl}_{2}$. The volume and salt concentration of this latter solution were such as to obtain the desired HA concentration (20-50 mg L${ }^{-1}$ ) and a calcium concentration of $40 \mathrm{mg} \mathrm{L}^{-1}$. Before use, the final solution was filtered through a RC $0.45 \mu \mathrm{m}$ membrane (Chemtek).

\subsection{Bath sorption tests}

A $40 \mathrm{~mL}$ aliquot of the HA solution, prepared as reported in the previous section, was added to the tuff (15-400 mg) in a $50 \mathrm{ml} \mathrm{screw-cap} \mathrm{vial} \mathrm{and} \mathrm{kept} \mathrm{at} \mathrm{room}$ temperature on a shaker at one oscillation per second. At selected times, aliquots were centrifuged at $15,000 \mathrm{rpm}$ for $15 \mathrm{~min}$ and analyzed by VIS-spectrometry at $450 \mathrm{~nm}$.

\subsection{Dynamic study by runs through tuff columns (breakthrough curves)}

A plastic column, $1.0 \mathrm{~cm}$ in diameter and $10.0 \mathrm{~cm}$ high, was packed with $10.0 \mathrm{~g}$ of NYT. The HA solution, $[\mathrm{HA}]=25 \mathrm{mg} \mathrm{L}^{-1},\left[\mathrm{CaCl}_{2}\right]=110 \mathrm{mg} \mathrm{L}^{-1}$ 
(corresponding to $\left[\mathrm{Ca}^{2+}\right]=340 \mathrm{mg} \mathrm{L}^{-1}$ ), $\mathrm{pH}=7.2$, concentration of $\mathrm{TrisH}^{+} / \mathrm{Tris}^{-}$ buffer $=0.01 \mathrm{M}$, was pumped downwards using a peristaltic pump at $3.0 \mathrm{~mL} \mathrm{~h}^{-1}$. Fractions of $6.5 \mathrm{~mL}$ were collected and analysed by visible spectroscopy. Before the sorption run, the column filled with tuff was eluted with $50 \mathrm{~mL}$ of a solution containing the Tris $\mathrm{H}^{+}$/Tris buffer and $\mathrm{CaCl}_{2}$ at the same concentrations as in the HA solution.

\section{Results and discussions}

\subsection{Calcium derivatives}

The total calcium and exchangeable-calcium contents of the two tuff derivatives tested in this study were significantly higher than in the raw material, the maximum values being measured in the form obtained by thermal treatment (type-2 derivative) (Table 2).

Table 2: Total calcium and exchangeable-calcium contents in untreated Neapolitan Yellow Tuff and Ca-enriched forms obtained by cation exchange at room temperature (type- 1 derivative) and by treatment with $\mathrm{CaCl}_{2}$ at $170{ }^{\circ} \mathrm{C}$ (type-2 derivative).

\begin{tabular}{|c|c|c|}
\hline Material & $\begin{array}{c}\text { Total } \mathrm{Ca} \\
(\text { as } \mathrm{CaO} \%)\end{array}$ & $\begin{array}{c}\text { Exchangeable Ca } \\
\text { (as CaO \%) }\end{array}$ \\
\hline Untreated & 2.9 & 1.6 \\
\hline Type-1 derivative & 4.7 & 3.3 \\
\hline Type-2 derivative & 5.9 & 4.2 \\
\hline
\end{tabular}

\subsection{Sorption}

The HA sorption ability of untreated NYT and $\mathrm{Ca}$ enriched forms has been analyzed by two methodologies: batch sorption tests to obtain sorption isotherms and flow methods through small column to obtain breakthrough curves. In order to simulate the composition of surface water, the HA solution was at $\mathrm{pH} 7.2$ and contained a low concentration of calcium ion $\left(30 \mathrm{mg} \mathrm{L}^{-1}\right)$. Figure 1 shows typical time-dependence curves of the HA sorption. As can be seen, the type-2 derivative exhibits the highest affinity for HA. Moreover as previously described in detail [11], the sorption of HA by the tuff samples continues for a long time.

Figure 2 reports the time-dependence curves for the sorption on Ca-enriched type-2 NYT derivative obtained using a higher starting HA concentration and different solid phase amounts.

Under all the experimental conditions tested we observed that the equilibrium was reached after more than one month.

Figure 3 shows the sorption isotherms for untreated NYT and Ca-enriched forms, recorded at various times. The curves in the figures have been obtained by fitting the experimental data using the Langmuir sorption equation: 


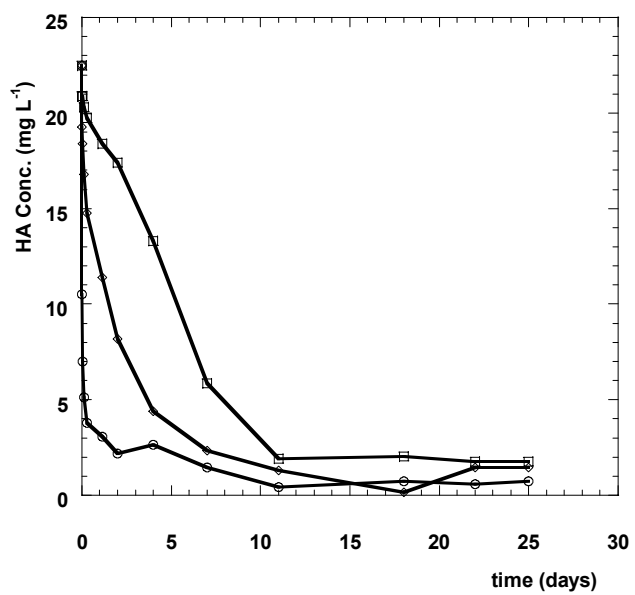

Figure 1: HA concentration in solution in function of the time of contact between the solution and untreated $(\square)$, Ca-enriched type-1 NYT derivative $(\diamond)$ and Ca-enriched type-2 NYT derivative (O). Experimental conditions: $350 \mathrm{mg}$ of solid phase, $45 \mathrm{ml} \mathrm{HA}$ solution, $\mathrm{pH}$ 7.2, $0.01 \mathrm{M}$ Tris $\mathrm{H}+/$ Tris buffer, room temperature.

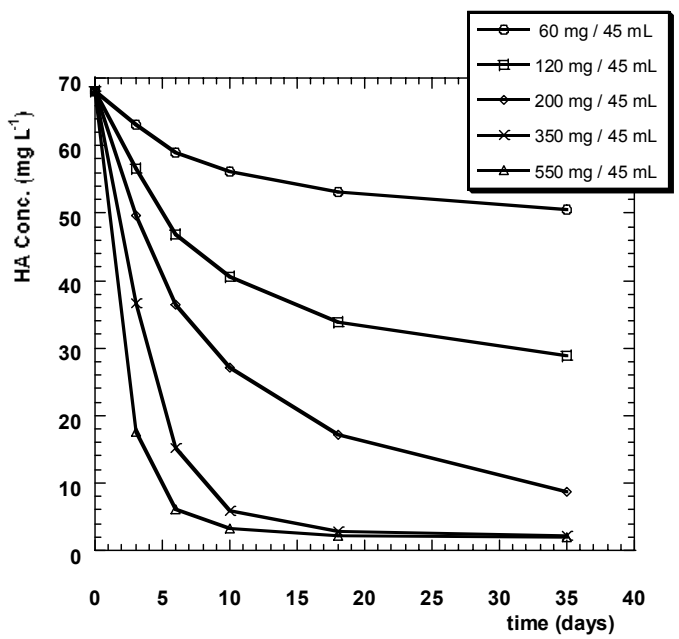

Figure 2: Time-dependence of the HA concentration in solution in contact with different amounts of type-2 NYT derivative; liquid phase: 45 $\mathrm{mL}, \mathrm{pH} 7.2,0.01 \mathrm{M}$ Tris $\mathrm{H}+/$ Tris buffer.

$$
\mathrm{q}=\mathrm{K} \mathrm{q}_{\mathrm{m}} \mathrm{C}_{\mathrm{e}} /\left(1+\mathrm{K} \mathrm{C}_{\mathrm{e}}\right)
$$

where $\mathrm{K}$ is the affinity constant and $\mathrm{q}_{\mathrm{m}}$ the maximum HA sorption amount.

Table 3 reports the $\mathrm{K}$ and $\mathrm{q}_{\mathrm{m}}$ values for the isotherms recorded at four selected times. The data for the raw tuff and that type-1 Ca-enriched form are 
similar to those reported formerly [11]. For all the samples, we observed that, in line with the trend shown in Fig. 1 and Fig. 2, increasing the contact time between the tuff and HA solution results in an increase of $\mathrm{q}_{\mathrm{m}}$. As regards the effects of $\mathrm{Ca}^{2+}$, it is interesting to note that increasing the amount of the bivalent metal (Tab. 1), both the maximum sorption capacity $\left(\mathrm{q}_{\mathrm{m}}\right)$ and the affinity constant (K) increase, as well.
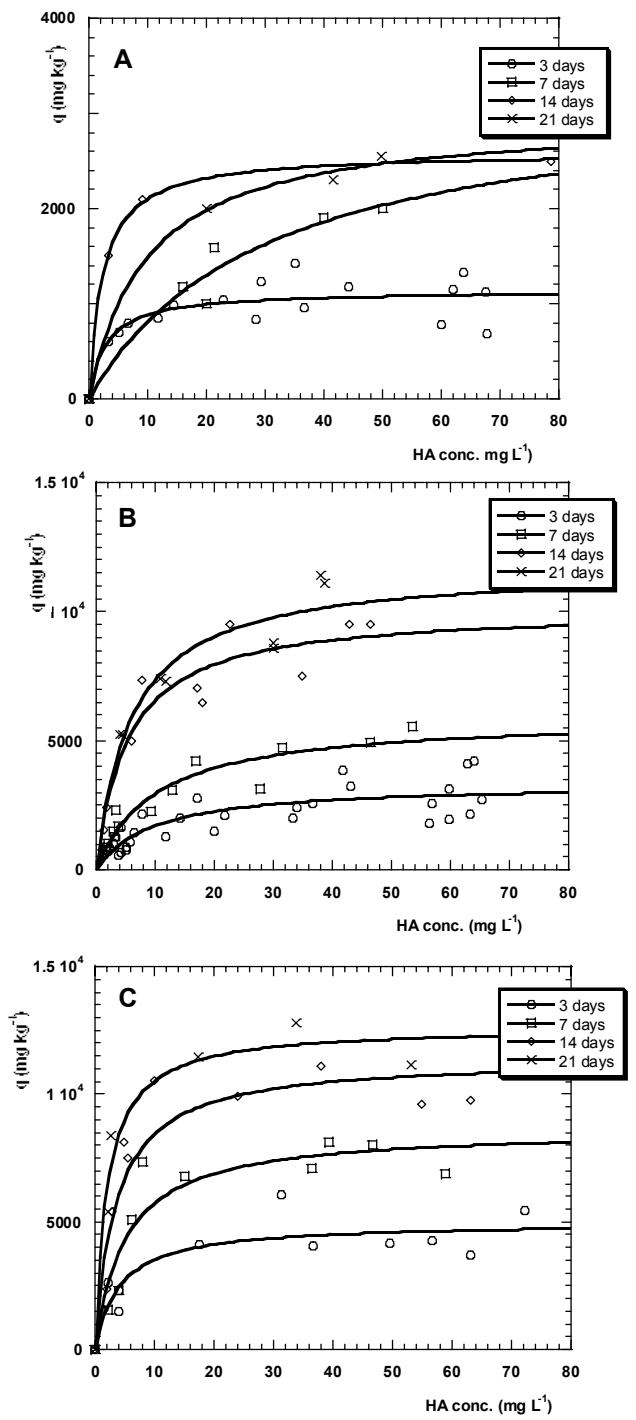

Figure 3: $\quad$ Humic acids sorption isotherms for untreated (A), type-1 (B) and type-2 (C) Ca-enriched NYT derivatives at different times. 
Table 3: Langmuir parameters for $\mathrm{HA}$ sorption by untreated and Caenriched derivatives of Neapolitan Yellow Tuff at four different incubation times: room temperature, solution $\mathrm{pH}=7.2$.

\begin{tabular}{lccc}
\hline Material & Time (days) & $\mathrm{K}\left(\mathrm{L} \mathrm{mg}^{-1}\right)$ & $\mathrm{q}_{\mathrm{m}}\left(\mathrm{mg} \mathrm{kg}^{-1}\right)$ \\
& & & \\
\hline Untreated & 3 & $0.4 \pm 0.3$ & $1100 \pm 200$ \\
& 7 & $0.03 \pm 0.01$ & $3300 \pm 200$ \\
& 14 & $0.4 \pm 0.3$ & $2700 \pm 300$ \\
& 21 & $0.10 \pm 0.03$ & $3000 \pm 200$ \\
Type-1 & 3 & $0.10 \pm 0.05$ & $3500 \pm 1000$ \\
derivative & 7 & $0.10 \pm 0.05$ & $6000 \pm 1000$ \\
& 14 & $0.20 \pm 010$ & $1000 \pm 1000$ \\
& 21 & $0.17 \pm 0.05$ & $11500 \pm 1000$ \\
Type-2 & & & \\
derivative & 3 & $0.25 \pm 0.10$ & $5000 \pm 1000$ \\
& 7 & $0.22 \pm 0.10$ & $8500 \pm 1000$ \\
& 14 & $0.28 \pm 0.10$ & $11500 \pm 1000$ \\
& 21 & $0.50 \pm 0.20$ & $13000 \pm 1000$ \\
\hline
\end{tabular}

An adsorption capacity of $2510 \mathrm{mg} \mathrm{kg}^{-1}$ has been reported for $\mathrm{HA}$ on commercial granulated carbon at $\mathrm{pH} 5.0$ [13], a value that is lower than the values recorded in this work for Ca-enriched NYT. Recently, values as high as $104,770 \mathrm{mg} \mathrm{kg}^{-1}$ and $53,000 \mathrm{mg} \mathrm{kg}^{-1}$ have been reported for surfactant-modified [8] and raw bentonite [14] at $\mathrm{pH}$ 3.0. Both these studies, however, report a marked reduction in the adsorption capacity at high $\mathrm{pH}$. For example, the adsorption capacity of raw bentonite decreased from $45,000 \mathrm{mg} \mathrm{kg}^{-1}$ to 26,000 $\mathrm{mg} \mathrm{kg}^{-1}$ for a $\mathrm{pH}$ variation from 5.0 to 6.0 .

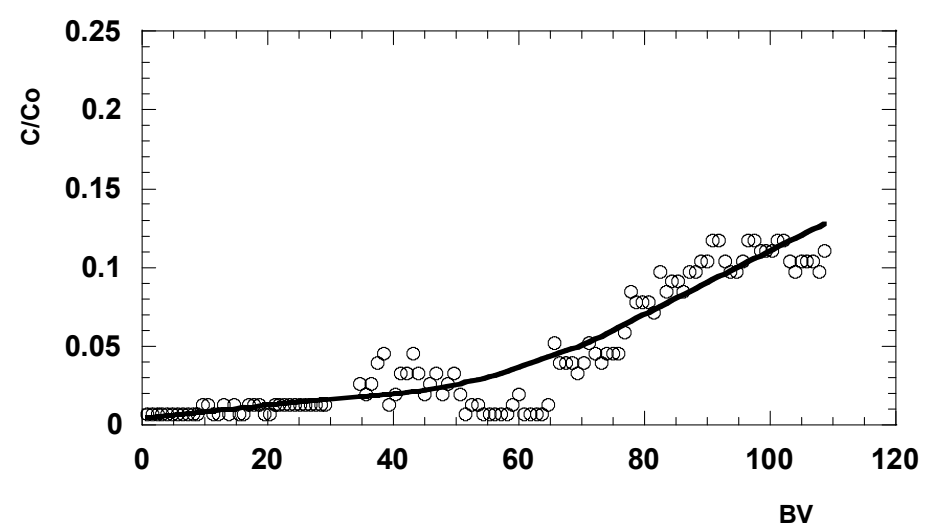

Figure 4: $\quad$ Humic acid breakthrough plot obtained eluting a column of type-2 Ca-enriched with $22.5 \mathrm{mg} \mathrm{L}^{-1}$ humic acid solution, $\mathrm{pH} 7.4,0.01 \mathrm{M}$ Tris buffer. $\mathrm{C}$ and $\mathrm{C}_{0}$ are the humic acid concentrations in effluent and influent, respectively; $\mathrm{BV}=$ bed volume of the column. 
Figure 4 shows the breakthrough curve for the sorption of humic acid by type-2 Ca-enriched NYT, obtained by eluting a small column of tuff with a humic acid solution at room temperature.

Feeding the column with a $22.5 \mathrm{mg} \mathrm{L}^{-1} \mathrm{HA}$ solution, the first 100 bed volumes of effluent solution contains a HA concentration lower than $10 \%$ of the influent solution.

\section{Conclusions}

This study shows that the Ca-enriched NYT is an effective sorbent for removing HA from water. Its adsorption capacity increases with the $\mathrm{Ca}$ content in the sample. The treatment of raw tuff with calcium salts in an oven at high temperature gives samples with a higher calcium amount. The sorption of HA on the material tested continues for a long time, an equilibrium being reached after more than one month. However, after few days of contact between the NYT samples and the HA solutions at neutral $\mathrm{pH}$ and room temperature, the amount of the HA adsorbed is already higher than that recorded for commercial activated carbon and, at least, comparable with the more promising materials recently tested.

\section{References}

[1] Cheng, W., Dastgheib, S.A. \& Karanfil, T., Adsorption of Dissolved Natural Organic Matter by Modified Activated Carbons. Water Research, 39(11), pp. 2281-2290, 2005.

[2] Moriguchi, T., Yano, K., Tahara, M. \& Yaguchi, K., Metal-modified silica adsorbents for removal of humic substances in water. Journal of Colloid and Interface Science, 283(2), pp. 300-310, 2005.

[3] Saito, T., Koopal, L.K., van Riemsdijk, W.H., Nagasaki, S. \& Tanaka, S., Adsorption of Humic Acid on Goethite: Isotherms, Charge Adjustments, and Potential Profiles. Langmuir, 20(3), pp. 689-700, 2004.

[4] Capasso, S., Colella, C., Coppola, E., Iovino, P. \& Salvestrini, S., Removal of humic substances from water by means of calcium-ion-enriched natural zeolites. Water Environmental Research, 79, pp. 305-309, 2007.

[5] Antelo, J., Arce, F., Avena, M., Fiol, S., Lopez, R. \& Macias, F., Adsorption of a soil humic acid at the surface of goethite and its competitive interaction with phosphate. Geoderma, 138(1), pp. 12-19, 2007.

[6] Abate, G., dos Santos, L.B.O., Colombo, S.M. \& Massini, J.C., Removal of fulvic acid from aqueous media by adsorption onto modified vermiculite. Applied Clay Science, 32, pp. 261-270, 2006.

[7] Wang, S., Gong, W., Liu, X., Gau, B. \& Yue, Q., Removal of fulvic acids using the surfactant modified zeolite in a fixed-bed reactor. Separation and Purification Technology, 51, pp. 367-373, 2006. 
[8] Anirudhan, T.S. \& Ramachandran, M., Surfactant-modified bentonite as adsorbent for the removal of humic acid from wastewater. Applied Clay Science, 35, pp. 276-281, 2007.

[9] Newsam, J.M., The zeolite cage structure. Science, 231, pp. 1093-1099, 1986.

[10] Capasso, S., Salvestrini, S., Coppola, E., Buondonno, A. \& Colella, C, Sorption of humic acid on zelitic tuff - A preliminary investigation. Applied Clay Science, 28, pp. 159-165, 2005.

[11] Capasso, S., Coppola, E., Iovino, P., Salvestrini, S. \& Colella, C., Sorption of humic acids on zeolitic tuffs. Microporous and Mesoporous Materials, 105, pp. 324-328, 2007.

[12] de' Gennaro, M. \& Langella, A., Italian zeolitized rocks of technological interest. Mineralium Deposita, 31, pp. 452-472, 1996.

[13] Chen, J.P. \& Wu, S., Simultaneous adsorption of copper and humic acids acid onto activated carbon. Journal of Colloid Interface Science, 280, pp. 334-342, 2004.

[14] Salman, M., El-Eswed, B. \& Khalili, F., Adsorption of humic acid on bentonite. Applied Clay Science, 38, pp. 51-56, 2007. 